\title{
Predictors of Pro-Environmental Behavior: A Comparison of University Students in the United States and China
}

\author{
Uchechi Onokala $^{1}$, Adeleke O. Banwo ${ }^{\text {1b }} \&$ Florence O. Okeowo ${ }^{2}$ \\ ${ }^{1}$ Department of Business Administration, University Of Lagos, Akoka. Lagos, Nigeria \\ ${ }^{1 b}$ Overseas Education College, Jiangsu University, Zhenjiang, China \\ ${ }^{2}$ Business Administration and Marketing Department, Babcock University, Nigeria \\ Correspondence: Adeleke O. Banwo, Overseas Education College, Jiangsu University, Zhenjiang, China.
}

Received: November 13, 2017 Accepted: January 11, $2018 \quad$ Online Published: February 26, 2018

doi:10.5539/jms.v8n1p127 URL: https://doi.org/10.5539/jms.v8n1p127

\begin{abstract}
Understanding and managing University student's environmental and sustainable behavior is critical to reducing global environmental problems and influencing pro-environmental behaviors. Survey data obtained from University students in different cities in the United States $(\mathrm{n}=75)$ and Chinese Students in Jiangsu Province, China $(n=109)$ were investigated and analyzed to identify major predictors of pro-environmental behaviors using the Comprehensive Action Determination Model. The results confirmed multiple factors such as Social norms, Intention to Act, Information Need and Situational factors significantly influence and shape the nature of pro-environmental behavior in the US and sets of Social norms, Intention to act, Environmental awareness, Information need and Situational factor in China. These findings are in consonance with the tenets of theory of planned behavior, norm activation theory; though the loading and effects differ in their local environment. University students in US showed higher level of pro-environmental behavior despite their individualistic society compared to Chinese students in China. The findings confirms the complexity of human behavior through the robustness of the comprehensive action determination model by showing that using unitary construct to predict environmental behavior is context specific and using different combinations of predictor variables exert significant influences in different local environments.
\end{abstract}

Keywords: Comprehensive Action Determination Model, University students, pro-environmental behavior, United States, Jiangsu province

\section{Introduction}

Human behavior is at the core of macro, meso and micro level sustainability and ecological problem such as climate change, environmental degradation, health hazard, pollution and imbalance in the global ecosystem (Clayton et al., 2015; Pan et al., 2016). In addition, major drivers of global ecological problems include "changes in population, age, structure, income, technology, relative prices, lifestyles, regulations and governance" (IPCC, 2014).

In the United States (US) and China, sustainability and environmental issues caused by human behavior have resulted in monumental problems in all facets of the economy. The global economy is concerned with the nature and level of these problems in these two countries due to their population size, level of industrialization and multiplier effects on global climate change. This is evidenced by the large body of literature and researchers studying the individual-environment behavior relationship in different local environments using different mix of variables (Steg et al., 2014; Moran \& Lopez, 2016; Unanue et al., 2016). Similarly, different perspectives and theories are used to describe actions relating to environmental and sustainability such as environment significant behaviors (Stern, 2000; Phipps et al., 2013), green behaviors (Kim et al., 2014), pro-environmental behavior (Osbaldiston \& Schott, 2011), ecological behaviors (Otto \& Kaiser, 2014), green consumer behaviors (Zhao et al., 2014). These apparent divergences in perspectives confirm the complexities in investigating facets of behavioral actions that enhance environmental sustainability.

Though environmental and sustainability problems are topical issues in US and China, some studies have used University students in a comparative study (Cordano et al., 2011; He et al., 2011). It is also apparent that US and China are distinct owing to the peculiarities of human behavior, legislations, culture and economic development, 
yet the underlying cause of these problems in both contexts is human behavior (Newhouse, 1990; Harper, 2015).

Globally, poor environmental behaviors contribute adversely to climate change and sustainability issues and result in the evolution of diverse theories and models in this domain. Interestingly, most of the early theories have their context in the United States; however, this has seen the usage and refinements in other local environment.

Researchers have applied theories such as theory of reasoned action (Ajzen, 1985; Ajzen, 2012), theory of planned behavior (Greaves et al., 2013), new environmental paradigm (Klöckner, 2013), norm activation theory (Cordano et al., 2011), value belief norms theory (Schwartz, 2012), comprehensive action determination theory (Klöckner, 2013) in investigating environmental behavior (Kim, 2016).

In recent times, there has been an upsurge in cross-cultural comparative studies (Cordano et al., 2011; De Leeuw et al., 2015; Soyez et al., 2015) using unitary and broad perspectives to examine pro-environmental behavior, but no study to the best of our knowledge has used Comprehensive Action Determination Theory in comparative studies between University students in USA and China.

In investigating these domains, this research recognized that several empirical evidences attest to usage of common variables like norms, intentions, context, perceived behavioral control, attitudes, cultures, age, sex as predictors and antecedents of pro-environmental behaviors. Nevertheless, harmonizing the variables has enhanced the understanding of motives and factors shaping individual level-environment behavior nexus. Thus, perspective based research, local contexts; samples used have influenced the type of theories and findings in literature. To ensure reliable measures, this study theoretical premise is Comprehensive Action Determination Theory due to its robustness and combination of different variables used in earlier theories.

The objectives of this study are: (1) to apply the theory's model in a cross-cultural setting and compare results. By comparing this theory in distinct contexts, we fill the gap in literature in the two countries amongst University students. (2) Identify factors that could be responsible for the variances among University students (3) discuss policy implications of our findings and offer future research directions.

\section{Explaining the Pro-environmental Behavior Construct}

Pro-environmental behavior (PEB) is multidimensional, multidisciplinary and complex construct that involves interplay of myriad of elements in any context (Gifford \& Nilsson, 2014; Larson et al., 2015). Defining this construct has remained complex and diverse perspectives adopted by scholars are attributable to its dynamic nature and scope (Jensen, 2002; Turaga et al., 2010; Robertson \& Barling, 2013). Hines et al. (1987) pioneering quantitative meta-analysis on responsible environment behavior showed the nature and strength of relationships of variables related and associated with pro-environmental behavior. They found that majority of the 128 studies used socio-structural variables to determine correlation and their meta-analysis provides a foundation premise, empirical base for the abundance of scholarly research related to pro-environmental behavior (Klöckner, 2013). Their findings show the existence of positive relationship between psychological, social constructs and pro-environmental behavior. These variables include pro-environmental attitudes, locus of control, behavior intentions and moral responsibility. The model highlights the interwoven nature and relationship actions, knowledge of requisite strategies, skills on one end of the continuum and attitudes, locus of control on the other end with intention as a determinant of pro-environmental behavior (Bamberg \& Möser, 2007). These set of psycho-social determinants spurred the wave of research and literature on the pro-environmental behavior paradigm.

Bamberg \& Möser (2007) in their meta-analysis adopted eight psycho-social determinants of pro-environmental behavior as against the four used by (Hines et al., 1987) in their pioneering studies using a dual methodology of structural equation modeling (SEM) and meta-analytic structural equation modeling. The usage of different approaches to investigate the antecedents of pro-environmental behaviors is due to complexities in understanding individual level behavioral tendencies. This study investigates the behavioral antecedents of University students because of their demographics and envisaged roles in making business and personal decisions that could be inimical or beneficial to the local and global environment. Pro-environmental behavior theory reveals variables that are intertwined and beneficial to this study. The comprehensive action determination model is used due to its robust framework and introduction of habit strength as a major antecedent of behavior.

\subsection{Comprehensive Action Determination Model (CADM)}

The shortcomings of the Theory of Reasoned Action led to Theory of Planned Behavior, Norm Activation Theory led to Value-Belief Norm Theory and other theoretical models used by different scholars. Superficially, using theories to explain human behaviors seems sequential as postulated in the models but the configuration of 
human behavior is complex, changing and contextual. Context cues, habit, environmental settings exert strong influences on behavioral intentions and actual behaviors. Attempts at investigating and understanding environmental behavior in different local environment has resulted in usage of these theories. Apparent shortcoming in each theory is traceable to their focus on some elements as key predictors of behavior failing to present a multidimensional and robust measurement of environmental behavior. Unitary behavior predictors like intentions is used in Azjen theory of planned behavior, Fishbein Theory of reasoned action, Personal norm in Norm -activation theory and habit in Triandis Theory. The need to synthesis all this variables is the main premise of the comprehensive action determination theory.

Klöckner \& Blöbaum (2010) Comprehensive action determination model suggest that intention, context and habits are principal determinants of behavior. Empirical studies reaffirms the importance of intention as a key mediator of direct predictors (Bamberg \& Möser 2007) and depending on the context, interplay of attitude, perceived behavioral control and norms exert multifaceted influences on intention in decision making process. They also reiterate the urgency and need to integrate the models to mitigate their individual limitations through adoption of a unified and robust model predicated on key elements and premise of TPB models. The comprehensive action determination model (CADM) argues that both Intention and perceived behavioral control do not suffice to predict pro-environmental behavior always and introduces habit strength as a major third predictor.

\subsection{Contextual Environmental Sustainability}

Global concern for environmental sustainability and pro-environmental behavior has increased in all spheres due to the universal nature of environmental degradation and severe climate change issues facing countries. "Continuing uncertainty about the severity and timing of climate-change impacts" (IPCC, 2014, p. 1). This has sustained the wave of cross-country research in different contexts with varied sample sizes. Some of these studies have used more than two countries to identify contextual and cultural issues that influence environmental behavior (See table 1). In addition, behavioral scientists, social psychologists, environmental proponents and advocates attempt to understand the level to which intrinsic and extrinsic factors shape participation in environmental causes.

Table 1. Cross-country study related to environmental and sustainability behavior.

\begin{tabular}{lll}
\hline Number & Names of Countries & Authors \\
\hline 5 & Austria, Czech, Italy, Netherlands, Sweden & (De Groot \& Steg, 2007), \\
2 & Slovenia (246) and France (215) & (Culiberg \& Elgaaied-Gambier, 2015) \\
2 & India and United States & (Gammoh et al., 2016) \\
5 & USA, Canada, Australia, Germany, Russia & (Soyez et al., 2015) \\
4 & USA, Spain, Mexico, Brazil & (Vicente-Molina et al., 2013) \\
2 & UK and Chile & (Unanue et al., 2016) \\
& USA and India & (Mancha \& Yoder, 2015) \\
2 & USA and Chile & (Cordano et al., 2011) \\
30 & 30 Countries & (Pisano \& Lubell, 2015) \\
\hline
\end{tabular}

\section{Method}

The study was limited to the largest countries in Asia and Americas, the United States and China. We selected the two countries due to their significant contribution to global sustainability issues, cultural differences and diverse local environmental problems. The focus on two countries made the process of survey design, translation, administration and collection of data easy when compared to other studies with larger cross-country survey. China and United States have distinct contextual and cultural environments which provides a good opportunity to apply comprehensive action determination model in both student population.

\subsection{Participants}

In Table 2, Participants comprised 109 Chinese students in China (T1) and 75 University students in US (T2), including $66(60 \%)$ female and $43(39 \%)$ male students in T1, $44(59 \%)$ female and $31(41 \%)$ male students in T2. Major age ranges in T1 are, below $21(55.9 \%)$ and $25.3 \%$ in T2, 21-30 (43.1\%) in T1 and $40 \%$ in T2, 31-40 $(1 \%)$ in $\mathrm{T} 1$ and $30.7 \%$ in $\mathrm{T} 2$. The educational qualifications of the participants in $\mathrm{T} 1$ and $\mathrm{T} 2$ are Undergraduate students $(84.4 \%$ and $30.7 \%$ ), Masters Students (15.6\% and $49.3 \%)$ and $20 \%$ doctorate students in T2. The educational qualification in T2 is more dispersed compared to the skewed composition in T1 (see Table 2). The online questionnaire in T2 was completed by University students living in Indianapolis (25\%), Texas (17\%), 
New York (15\%), New Jersey (13\%), Pennsylvania (9\%), Detroit(7\%), North Carolina (5\%) and Maryland (4\%) while location of students in $\mathrm{T} 1$ were across cities in Jiangsu province.

Table 2. Profile of respondents

\begin{tabular}{llllll}
\hline Sex ( US ) & Frequency & Percentage & Sex (China) & Frequency & Percentage \\
\hline Male & 31 & 41 & Male & 43 & 39 \\
Female & 44 & 59 & Female & 66 & 60 \\
Total & 75 & 100 & Total & 109 & 99 \\
Age & Frequency & Percentage & Age & Frequency & Percentage \\
Below 21 & 19 & 25.3 & Below 21 & 61 & 55.9 \\
$21-30$ & 30 & 40.0 & $21-30$ & 47 & 43.1 \\
$31-40$ & 23 & 30.7 & $31-40$ & 1 & 1 \\
$41-50$ & 3 & 4.0 & $41-50$ & 0 & 0 \\
Total & $\mathbf{7 5}$ & $\mathbf{1 0 0 . 0}$ & & $\mathbf{1 0 9}$ & $\mathbf{1 0 0}$ \\
\hline Educational & Frequency & Percentage & Educational & Frequency & Percentage \\
Qualifications & & & Qualifications & & \\
Undergraduate students & 23 & 30.7 & Undergraduate students & 92 & 84.4 \\
Masters student & 37 & 49.3 & Masters student & 17 & 15.6 \\
Doctoral Student & 15 & 20.0 & Doctoral Student & 0 & 0 \\
Total & $\mathbf{7 5}$ & $\mathbf{1 0 0}$ & & $\mathbf{1 0 9}$ & $\mathbf{1 0 0}$ \\
\hline
\end{tabular}

\subsection{Measures}

Blok et al. (2015) questionnaire was adapted and self-report habit index was added (Verplanken \& Orbell, 2003). The major measures Sustainable Behavior, Attitude, Information need, Intention to act, Environmental awareness, Perceived behavioral control, Situational factors, Social Norms and Habit strength are described below:

Sustainable Behavior: To measure sustainable behavior students were asked to indicate the extent to which they engaged in the following sustainable behaviors relating to energy use, printing, sustainable consumption, shopping, computer use, light use and recycling using a 5 point Likert type scale from $1=$ never to $5=$ always.

Attitude to Pro-Environmental Behavior: measured students attitude to pro-environmental behavior in the University with some items "I am in favor of behaving pro-environmentally in the University". "I think the pro-environmental behavior in the University is good", "I was briefed of pro-environmental behavior in my university", "I think too much attention is given to pro-environmental behavior" on a 5 point Likert scale ranging from 1 (strongly disagree) to 5 (strongly agree), a high score indicated positive PEB attitude and vice-versa.

Information Need: Students information need was obtained by asking them, whether they want to be informed about environmental impacts of their behavior, environmental initiatives, learning opportunities for environmental friendly behaviors and cost of energy, water and paper used in their department and groups. All the items were scaled from 1 (Never) to 5 (Always).

Environmental Awareness: was measured by using 8 scales out of the 12-item scale to assess student's level of environmental awareness (Gatersleben et al., 2002). Items included "Environmental pollution affects my health". "I walk often within the University rather than taking a car/cab/bike". "I commute daily to classes by driving". "I use public transport like buses and cabs"; "Environmental problems have consequences for my life"; "I am unaware of the effect of my behavior on the environment" "Environmental problems are a risk for the future of my children"; "I use my phone daily and switch off my phones when I want to sleep"; on scales ranging from 1 (Never) to 5 (Always).

Perceived Behavior control : Students ability to engage in pro-environmental behavior within the University is measured by four items and a low score implies low perceived behavior control and inability to practice environmental behaviors and high score shows high ability of perceived behavior control.

Situational Factors: measured contextual issues in the University that could enhance or inhibit student's ability to exhibit positive environmental behaviors. The three item questions depicted the ease and difficulty in each situation and responses were measured on a 5 point scale from strongly disagree to strongly agree. The lower the score the more difficult the possibility for employee to act in an environmental friendly manner.

Verplanken \& Orbell (2003) Self-Report Habit Index 12-items were measured with a 5-point scale from strongly to strongly agree. A low score confirms low or poor habit strength and a high score suggest high habit strength 
could take precedence over context.

Basic day to day activities such as usage of air-conditions, printing, drinking, computer use, light use and recycling were used to measure employee's pro-environmental behavior.

A 5-point Likert scale from 1 to 5 (Never to Always) was used von Borgstede \& Biel (2002). For Social Norm, a 4 item construct was included to test (normative) employees opinion of what their colleagues should do at work (Print double sided, copy double sided, recycle and turn off computer when not in use). The outcomes were evaluated on a 5-point Likert scale ranging from 1-absolutely not to 5-Absolutely.

\section{Results}

For data analysis, SPSS Version 22 was used. The reliability of the scale items was measured by Cronbach's alpha to confirm internal consistency and correlation. Cronbach alpha $(\alpha)$ based on standardized items was $\alpha$ $=.84$ and $.79 \mathrm{in} \mathrm{T} 1$ and $\mathrm{T} 2$ and good since its above 0.7 based on recommendations of (Nunnally \& Bernstein, 1994; Blok et al., 2015). The R 2 is 0.30 meaning that approximately $30 \%$ of the variability is accounted for by the variables in the model. The data, met the assumption of independent errors in both $\mathrm{T} 1$ and $\mathrm{T} 2$ (Durbin-Watson value $=1.87,2.16$ ) see Table 3. In addition, an analysis of standard residual values was conducted to identify any outliers, which showed that the data contained no outliers for T1 (Std.Residual Min= -2.90, Std.Residual Max=2.37) and T2 (Std.Residual Max=2.30).

Table 3, shows principal component analysis (PCA) and Varimax orthogonal rotation was used to test if the data is suitable to identify factor dimensions and measures of sampling adequacy. The Kaiser-Myer-Olkin statistics in T1 and T2 (.83 and .75) are above the benchmark of .50 also Bartlett values in both samples T1 and T2 (359.47 and 194.22) are significant at 5\% and confirms suitability for factor dimensions.

Table 3. Reliability statistics and stepwise regression, China (T1), US (T2)

\begin{tabular}{|c|c|c|c|c|c|c|}
\hline Cronbach's Alpha & $\begin{array}{l}\text { Cronbach's Alpha } \\
\text { Based on } \\
\text { Standardized Items } \\
\end{array}$ & $\mathrm{N}$ of Items & Cronbach's Alpha & $\begin{array}{l}\text { Cronbach's Alpha Based on } \\
\text { Standardized Items }\end{array}$ & N of Items & \\
\hline .784 & .792 & 10 & .834 & .838 & 10 & \\
\hline $\begin{array}{lrl}\text { US(T2) KMO and } \\
\text { Bartletts's Test }\end{array}$ & & & $\begin{array}{l}\text { China(T1) KMO and } \\
\text { Bartletts's Test }\end{array}$ & & & \\
\hline $\begin{array}{l}\text { Kaiser-Meyer-Olkin } \\
\text { Measure of Sampling }\end{array}$ & & \begin{tabular}{|c|}
.754 \\
\end{tabular} & $\begin{array}{l}\text { Kaiser-Meyer-Olkin } \\
\text { Measure of Sampling } \\
\end{array}$ & & .826 & \\
\hline \multirow[t]{3}{*}{ 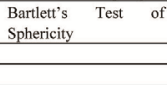 } & Approx.Chi.Square & 194.220 & Bartlett's Test of Sphericity & Approx. Chi. Square & 359.469 & \\
\hline & $\mathrm{df}$ & 45 & & df & 45 & \\
\hline & Sig & .000 & & Sig & .000 & \\
\hline \multicolumn{7}{|c|}{\begin{tabular}{lrr|l|} 
US & (T2) & Model & \\
Summary" & & \\
\end{tabular}} \\
\hline Model & $\mathrm{R}$ & \begin{tabular}{|l} 
R Square \\
\end{tabular} & \begin{tabular}{|l} 
Adjusted R Square \\
\end{tabular} & Std. Error of the Estimate & Durbin-Watson & \\
\hline 1 & $.548^{\mathrm{a}}$ & .300 & .203 & .496 & 2.159 & \\
\hline a. Predictors(Constant), & $\begin{array}{l}\text { HABTOTAL, } \\
\text { SITTOTAL }\end{array}$ & SNTOTAL & SUSTOTAL & PBCTOTAL, EATOTAL & INTACTTOTAL & \begin{tabular}{|l} 
ATTTOTAL \\
\end{tabular} \\
\hline \multicolumn{7}{|c|}{\begin{tabular}{ll|l} 
CHINA (T1) Model & \\
Summary $^{\mathrm{b}}$ &
\end{tabular}} \\
\hline Model & $\mathrm{R}$ & \begin{tabular}{|l|l} 
R Square \\
\end{tabular} & \begin{tabular}{|l} 
Adjusted R Squarc \\
\end{tabular} & Std. Error of the Estimatc & \begin{tabular}{|l|} 
Durbin-Watson \\
\end{tabular} & \\
\hline 1 & $.538^{\mathrm{a}}$ & .289 & .208 & 374 & 1.867 & \\
\hline a.Predictors(Constant), & $\begin{array}{l}\text { HABTOTAL, } \\
\text { INTACTTOTAL }\end{array}$ & SNTOTAL & SUSTOTAL & PBCTOTAL, EATOTAL & \begin{tabular}{|l} 
INFNTOTAL \\
\end{tabular} & \\
\hline ATTTOTAL,Age, & Gender & & & b. Dependent Variable: & PEBTOTA & \\
\hline US(T2) ANOVA & & Sum of Squares & df & Mean Square & $\mathbf{F}$ & \\
\hline \multirow[t]{3}{*}{ Model } & $\begin{array}{l}\text { Regression } \\
\end{array}$ & 6.869 & 9 & .763 & 3.099 & $.004^{b}$ \\
\hline & Residual & 16.009 & 65 & .246 & & \\
\hline & Total & 22.077 & 74 & & & \\
\hline a. Dependent Variable: & $\begin{array}{l}\text { PEBTOTA } \\
\end{array}$ & & & & & \\
\hline \multirow[t]{2}{*}{ b. Predietors:(Constant) } & SUSTOTAL,Age & \begin{tabular}{|l|} 
SITTOTAL \\
\end{tabular} & Gender & INFNTOTAL & \begin{tabular}{|l|} 
SNTOTAL \\
\end{tabular} & \begin{tabular}{|l} 
HABTOTAL, \\
\end{tabular} \\
\hline & EATOTAL & \begin{tabular}{|l|} 
ATTTOTAL \\
\end{tabular} & \begin{tabular}{|l} 
PBCTOTAL \\
\end{tabular} & INTACTTOTAL & & \\
\hline CHINA(T1) ANOVA & & Sum of Squares & df & Mean Square & $\mathbf{F}$ & \\
\hline \multirow[t]{3}{*}{ Model } & Regression & \begin{tabular}{|l|l|}
5.468 \\
\end{tabular} & 11 & .763 & 3.550 & $.000^{\mathrm{b}}$ \\
\hline & Residual & 13.442 & 96 & .246 & & \\
\hline & Total & 28.910 & 107 & & & \\
\hline a. Dependent Variable: & PEBTOTA & & & & & \\
\hline \multirow[t]{2}{*}{$\begin{array}{ll}\text { b. } & \text { Predictors: } \\
\text { (Constant) } & \\
\end{array}$} & SUSTOTAL,Age & SITTOTAL & Gender & \begin{tabular}{|l} 
INFNTOTAL \\
\end{tabular} & SNTOTAL & \begin{tabular}{|l} 
HABTOTAL \\
\end{tabular} \\
\hline & EATOTAL & ATTTOTAL & PBCTOTAL & INTACTTOTAL & & \\
\hline $\begin{array}{l}\text { Stepwise } \\
\text { Regression:US (T2) }\end{array}$ & $\begin{array}{l}\text { Variables Entered/ } \\
\text { Removed }^{\mathrm{A}}\end{array}$ & & $\begin{array}{l}\text { Stepwise Regression: } \\
\text { CHINA (T1) }\end{array}$ & \begin{tabular}{|l|} 
Variables \\
Entered/Removed $^{\mathrm{a}}$
\end{tabular} & & \\
\hline Model & Variables Entered & Method & Model & Variables Entered & \begin{tabular}{|l|} 
Variables Removed \\
\end{tabular} & \begin{tabular}{|l} 
Method \\
\end{tabular} \\
\hline 1 & SUSTOTAL & $\begin{array}{ll}\text { Stepwise } \quad \text { (Criteria: } \\
\text { Probability-of-F-to-enter } \\
<=\quad .050, \\
\text { Probability-of-F-to-remov } \\
\mathrm{c}>=.100 \text { ) }\end{array}$ & 1 & SNTOTAL & $\begin{array}{|lr|}\text { Stepwise } \quad \text { (Criteria: } \\
\text { Probability-of-F-to-enter } \\
<=\quad .050, \\
\text { Probability-of-F-to-remo } \\
\text { ve }>=.100)\end{array}$ & \\
\hline 2 & HABTOTAL & $\begin{array}{l}\text { Stepwise } \quad \text { (Criteria: } \\
\text { Probability-of-F-to-enter } \\
<= \\
\text { Probability-of-F-to-remov } \\
\mathrm{e}>=.100 \text { ) }\end{array}$ & 2 & EATOTAL & $\begin{array}{lr}\text { Stepwise } \quad \text { (Criteria: } \\
\text { Probability-of-F-to-enter } \\
<= & .050, \\
\text { Probability-of-F-to-remo } \\
\text { ve }>=.100 \text { ) }\end{array}$ & \\
\hline \multirow[t]{2}{*}{3} & EATOTAL & $\begin{array}{l}\text { Stepwise } \quad \text { Criteria: } \\
\text { Probability-of-F-to-enter } \\
<=\quad .050 \text {, } \\
\text { Probability-of-F-to-remov } \\
\text { e }>=.100) \\
\end{array}$ & & & & \\
\hline & & & & $\begin{array}{ll}\text { a. Dependent Variable: } \\
\text { PEBTOTA }\end{array}$ & & \\
\hline
\end{tabular}


The linear combination of the predictor variables was significantly related to Pro-environmental behavior F (11, $96)=3.550, p<.001$. The multiple correlation coefficients was .54 indicating that approximately $54 \%$ of the variance of pro-environmental behavior is accounted for by the linear combination of all the predictor variables.

Table 4. Descriptive statistics

\begin{tabular}{llllllll}
\hline China (T1) & Mean & Std.Deviation & $\mathrm{N}$ & US (T2) & Mean & Std.Deviation & $\mathrm{N}$ \\
\hline PEBTOTA & 2.96 & .434 & 109 & PEBTOTA & 3.19 & .556 & 75 \\
SUSTOTAL & 3.35 & .455 & 109 & SUSTOTAL & 3.57 & .589 & 75 \\
ATTTOTAL & 3.54 & .513 & 109 & ATTTOTAL & 3.67 & .643 & 75 \\
INFNTOTAL & 3.62 & .911 & 109 & INFNTOTAL & 3.91 & .828 & 75 \\
INTACTTOTAL & 3.78 & .878 & 109 & INTACTTOTAL & 3.97 & .775 & 75 \\
EATOTAL & 3.67 & .599 & 109 & EATOTAL & 3.82 & .576 & 75 \\
PBCTOTAL & 3.47 & .653 & 109 & PBCTOTAL & 3.73 & .661 & 75 \\
SITTOTAL & 3.65 & .675 & 109 & SITTOTAL & 3.89 & .649 & 75 \\
SNTOTAL & 4.19 & .802 & 109 & SNTOTAL & 4.20 & .744 & 75 \\
HABTOTAL & 3.36 & .707 & 109 & HABTOTAL & 3.60 & .748 & 75 \\
\hline
\end{tabular}

The descriptive statistics are presented in Table 4. Participants $(n=109, n=75)$ reported differently on the constructs. Students Pro-environmental behavior (PEBTOTA) in T2 $(\mathrm{M}=3.19, \mathrm{SD}=0.56)$ was much higher than $\mathrm{T} 1(\mathrm{M}=2.96, \mathrm{SD}=0.43)$. Students reported highest mean scores for Social Norms (SNTOTAL) in $\mathrm{T} 1(\mathrm{M}=4.19$, $\mathrm{SD}=0.80), \mathrm{T} 2(\mathrm{M}=4.20, \mathrm{SD}=0.74)$ and Intention to act (INTACTTOTAL), $(\mathrm{M}=3.78, \mathrm{SD}=0.88)$ in $\mathrm{T} 1$ and $\mathrm{T} 2$ $(\mathrm{M}=3.97, \mathrm{SD}=0.77)$. This implies that social norms and intention to act exerted much influence on their pro-environmental behavior. Students in T2 indicated more interest for information need (INFNTOTAL), $(\mathrm{M}=3.91, \mathrm{SD}=0.83)$ compared to students in $\mathrm{T} 1(\mathrm{M}=3.62, \mathrm{SD}=0.911)$ and this could have influenced the higher level of pro-environmental behavior in T2. Though students in both contexts reported high scores for environmental awareness (EATOTAL) in $\mathrm{T} 1(\mathrm{M}=3.67, \mathrm{SD}=0.59), \mathrm{T} 2(\mathrm{M}=3.82, \mathrm{SD}=0.58)$, it did not significantly influence their sustainable behavior (SUSTOTAL), T1 $(\mathrm{M}=3.35, \mathrm{SD}=0.45), \mathrm{T} 2(\mathrm{M}=3.57, \mathrm{SD}=0.59)$. We also find that students attitude $(\mathrm{T} 1, \mathrm{M}=3.54, \mathrm{SD}=0.51: \mathrm{T} 2, \mathrm{M}=3.67, \mathrm{SD}=0.64)$ towards pro-environmental behavior was much lower than situational factors ( $\mathrm{T} 1, \mathrm{M}=3.65, \mathrm{SD}=0.67: \mathrm{T} 2, \mathrm{M}=3.89, \mathrm{SD}=0.65)$. This could have arisen due to high scores reported for perceived behavior control (PEBTOTAL) (T1, M=3.47, $\mathrm{SD}=0.65: \mathrm{T} 2, \mathrm{M}=3.73, \mathrm{SD}=0.66$ ) that possibly limited activation of positive environmental behaviors. Compared to other variables, students reported low habit scores (T1, $\mathrm{M}=3.36, \mathrm{SD}=0.71: \mathrm{T} 2, \mathrm{M}=3.60, \mathrm{SD}=0.75$ ).

Furthermore, steps wise regression was conducted to determine the best combination of the independent variables that significantly predicted the dependent variable. In T1, Social Norm and Environmental Awareness were the main predictors of students' pro-environmental behavior and in T2, only three predictors, Sustainable behavior, Habit and Environmental Awareness predicted and influenced significantly student's pro-environmental behavior (see Table 4).

\section{Discussions}

Using comprehensive action determination model, we investigated predictor variables of pro-environmental and sustainability behaviors among University students in China and United states. Different predictors influenced students pro-environmental behavior in both China and US. The results confirmed multiple factors such as Social norms, Intention to Act, Information Need and Situational factors that significantly influence and shape the nature of environmental behavior in T2; sets of Social norms, Intention to act, Environmental awareness, Information need and Situational factor in T1. This findings are in consonance with the tenets of theory of planned behavior (Ajzen, 2015), norm activation theory, though the loading and effects differ in both context.

The University environment, spatial relationship and interactions had a strong influence on social norms, other factors such as culture (Hofstede et al., 1991; Cordano et al., 2011) and collectivist nature of Chinese society would have influenced Chinese students pro-environmental behavior ( $\mathrm{Li}$ et al., 2014). Conversely, though students in T2 belong to an individualistic society (Gorodnichenko \& Roland, 2016), they displayed higher social norms, which could have arisen from their high level of environmental awareness. Furthermore, the results on automaticity of past behavior to predict future behavior and habit is reflected in the different effect habit strength has on pro-environmental behavior and consistent with similar findings (Verplanken \& Aarts, 1999; Bargh, 2013). Second, our findings on the stepwise regression indicate and confirm the robustness of the comprehensive action determination model by showing that using unitary construct to predict environmental 
behavior may be context specific but rather different combinations of predictor variables exert significant influences in different contexts. Third, we found that University students in US showed higher level of pro-environmental behavior despite their individualistic society compared to Chinese students in China. This finding is contrary to our expectations as we expected social norms to be stronger in collectivist society; however, this opens a new vista of inquiry on contextual strategies to increase and promote pro-environmental behavior among University students in China.

\subsection{Policy Implications}

The findings offer practical understanding of key predictor variables of pro-environmental behavior among University students in US and China. The results suggest variations in the main predictor variables in both context and their interwoven nature. Thus, policy makers must redesign environmental education programs and initiatives to be more practical. The direct and indirect relationship found among the predictor variables has important implications for researchers, local environmental agencies and designers of educational programs in the University (Klöckner, 2013). There is a need for a contextual approach to fostering pro-environmental behaviors among University Students because of the diversity of their demographics and culture (Kohler, 2003; Marks et al., 2016). We recognize that due to the changing lifestyles of University students; promoting and inculcating positive pro-environmental behavior modification initiatives requires using diverse social and psychological appeals by all stakeholders at the micro and macro level. Based on the findings on the effect of social norms, we suggest that policy makers use youth environmental champions to influence positive social norms (Cordano et al., 2003; Pollock \& Whitelaw, 2005; Wood et al., 2016). Local initiatives should include designing of basic information to overcome knowledge gap and increase environmental awareness. Universities and other agencies need to use the right channels that appeals to students in a manner that shows immediate and long-term benefit.

A fundamental implication of thisr study is that policy makers and environmental stakeholders must recognize time factor and ensure policies and intervention strategies are continuous and adapted in response to changes in the local environment (De Young, 2013).

\section{Limitation and Future Research Directions}

This research context was limited to University students in the United States (US) and within Jiangsu Province, China. The educational qualification of sampled students in the US is more dispersed, majority of sampled students in China are Undergraduate students and this could have influenced the findings. Also, self-report online questionnaires were used in both contexts, though this is commonly used in the environmental behavior research, it is often subject to social desirability bias issues (Krumpal, 2013; Dodou \& De Winter, 2014). Another limitation is the differences in the sample size, this could affect the generalization of the findings in other contexts and thus other studies should include appropriate sample sizes (Barlett et al., 2001). Similarly, we found out that the questionnaire length affected response and completion rate, other studies should use appropriate length and consider the attitude of respondents. Students are usually averse to completing lengthy questionnaires online and usage of hard copies is not environmentally friendly where the sample size is very large. Vésteinsdóttir et al. (2017) also advance using short and appropriate scales in questionnaires. The usage of purposive sampling is another major limitation, nevertheless it still enjoys usage by different scholars in their studies (Tongco, 2007). This method was chosen to have access to the hard to reach English speaking Chinese Students in China, nevertheless it might not be representative of the entire student population in Jiangsu Province (Atkinson \& Flint, 2001).

\section{References}

Ajzen, I. (1985). From intentions to actions: A theory of planned behavior. Berlin: Springer. https://doi.org/10.1007/978-3-642-69746-3_2

Ajzen, I. (2012). Martin Fishbein's legacy the reasoned action approach. The Annals of the American Academy of Political and Social Science, 640(1), 11-27. https://doi.org/10.1177/0002716211423363

Ajzen, I. (2015). The theory of planned behaviour is alive and well, and not ready to retire: a commentary on Sniehotta, Presseau, and Araújo-Soares. Health Psychology Review, 9(2), 131-137. https://doi.org/10.1080/17437199.2014.883474

Atkinson, R., \& Flint, J. (2001). Accessing hidden and hard-to-reach populations: Snowball research strategies. Social Research Update, 33(1), 1-4.

Bamberg, S., \& Möser, G. (2007). Twenty years after Hines, Hungerford, and Tomera: A new meta-analysis of psycho-social determinants of pro-environmental behaviour. Journal of Environmental Psychology, 27(1), 
14-25. https://doi.org/10.1016/j.jenvp.2006.12.002

Bargh, J. A. (2013). Social psychology and the unconscious: The automaticity of higher mental processes. London: Psychology Press.

Barlett, J. E., Kotrlik, J. W., \& Higgins, C. C. (2001). Organizational research: Determining appropriate sample size in survey research. Information Technology, Learning, and Performance Journal, 19(1), 43.

Blok, V., Wesselink, R., Studynka, O., \& Kemp, R. (2015). Encouraging sustainability in the workplace: a survey on the pro-environmental behaviour of university employees. Journal of Cleaner Production, 106, 55-67. https://doi.org/10.1016/j.jclepro.2014.07.063

Clayton, S., Devine-Wright, P., Stern, P. C., Whitmarsh, L., Carrico, A., Steg, L., ... Bonnes, M. (2015). Psychological research and global climate change. Nature Climate Change, 5(7), 640-646. https://doi.org/10.1038/nclimate2622

Cordano, M., Ellis, K. M., \& Scherer, R. F. (2003). Natural capitalists: Increasing business students' environmental sensitivity. Journal of Management Education, 27(2), 144-157. https://doi.org/10.1177/1052562903251417

Cordano, M., Welcomer, S., Scherer, R. F., Pradenas, L., \& Parada, V. (2011). A cross-cultural assessment of three theories of pro-environmental behavior a comparison between business students of Chile and the United States. Environment and Behavior, 43(5), 634-657. https://doi.org/10.1177/0013916510378528

De Leeuw, A., Valois, P., Ajzen, I., \& Schmidt, P. (2015). Using the theory of planned behavior to identify key beliefs underlying pro-environmental behavior in high-school students: Implications for educational $\begin{array}{lllll}\text { interventions. Journal of Environmental Psychology, } & 42, & 128-138 .\end{array}$ https://doi.org/10.1016/j.jenvp.2015.03.005

De Young, R. (2013). Environmental psychology overview. Green organizations: Driving Change with IO Psychology, 22-45.

Dodou, D., \& De Winter, J. (2014). Social desirability is the same in offline, online, and paper surveys: a meta-analysis. Computers in Human Behavior, 36, 487-495. https://doi.org/10.1016/j.chb.2014.04.005

Gatersleben, B., Steg, L., \& Vlek, C. (2002). Measurement and determinants of environmentally significant $\begin{array}{llll}\text { consumer behavior. } & \text { Environment and 345-362. }\end{array}$ https://doi.org/10.1177/0013916502034003004

Gifford, R., \& Nilsson, A. (2014). Personal and social factors that influence pro-environmental concern and behaviour: A review. International Journal of Psychology, 49(3), 141-157. https://doi.org/10.1002/ijop.12034

Gorodnichenko, Y., \& Roland, G. (2016). Culture, institutions and the wealth of nations. Review of Economics and Statistics. https://doi.org/10.1162/rest_a_00599

Greaves, M., Zibarras, L. D., \& Stride, C. (2013). Using the theory of planned behavior to explore environmental behavioral intentions in the workplace. Journal of Environmental Psychology, 34, 109-120. https://doi.org/10.1016/j.jenvp.2013.02.003

Harper, C. (2015). Environment and society. London, New York: Routledge.

He, X., Hong, T., Liu, L., \& Tiefenbacher, J. (2011). A comparative study of environmental knowledge, attitudes and behaviors among university students in China. International Research in Geographical and Environmental Education, 20(2), 91-104. https://doi.org/10.1080/10382046.2011.564783

Hines, J. M., Hungerford, H. R., \& Tomera, A. N. (1987). Analysis and synthesis of research on responsible environmental behavior: A meta-analysis. The Journal of Environmental Education, 18(2), 1-8. https://doi.org/10.1080/00958964.1987.9943482

Hofstede, G., Hofstede, G. J., \& Minkov, M. (1991). Cultures and organizations: Software of the mind. Citeseer.

Jensen, B. B. (2002). Knowledge, action and pro-environmental behaviour. Environmental Education Research, 8(3), 325-334. https://doi.org/10.1080/13504620220145474

Kim, A., Kim, Y., Han, K., Jackson, S. E., \& Ployhart, R. E. (2014). Multilevel influences on voluntary workplace green behavior individual differences, leader behavior, and coworker advocacy. Journal of Management. https://doi.org/10.1177/0149206314547386

Kim, H. T. C. (2016). Christian A. Klöckner, The Psychology of Pro-Environmental Communication: Beyond 
Standard Information Strategies. International Journal of Communication, 10(4).

Klöckner, C. A. (2013). A comprehensive model of the psychology of environmental behaviour-A $\begin{array}{llll}\text { meta-analysis. Global } & \text { Environmental }\end{array}$ https://doi.org/10.1016/j.gloenvcha.2013.05.014

Klöckner, C. A., \& Blöbaum, A. (2010). A comprehensive action determination model: Toward a broader understanding of ecological behaviour using the example of travel mode choice. Journal of Environmental Psychology, 30(4), 574-586. https://doi.org/10.1016/j.jenvp.2010.03.001

Kohler, N. (2003). Cultural issues for a sustainable built environment. Buildings, culture and environment: Informing Local and Global Practices, 83-108. https://doi.org/10.1002/9780470759066.ch6

Krumpal, I. (2013). Determinants of social desirability bias in sensitive surveys: a literature review. Quality \& Quantity, 47(4), 2025-2047. https://doi.org/10.1007/s11135-011-9640-9

Larson, L. R., Stedman, R. C., Cooper, C. B., \& Decker, D. J. (2015). Understanding the multi-dimensional structure of pro-environmental behavior. Journal of Environmental Psychology, 43, 112-124. https://doi.org/10.1016/j.jenvp.2015.06.004

Li, D., Remedios, L., \& Clarke, D. (2014). Chinese students' groupwork practices and experiences in China. Higher Education, 68(2), 227-241. https://doi.org/10.1007/s10734-013-9704-y

Marks, M., Chandler, L., \& Baldwin, C. (2016). Re-imagining the environment: using an environmental art festival to encourage pro-environmental behaviour and a sense of place. Local Environment, 21(3), 310-329. https://doi.org/10.1080/13549839.2014.958984

Moran, E. F., \& Lopez, M. C. (2016). Future directions in human-environment research. Environmental Research, 144, 1-7. https://doi.org/10.1016/j.envres.2015.09.019

Newhouse, N. (1990). Implications of attitude and behavior research for environmental conservation. The Journal of Environmental Education, 22(1), 26-32. https://doi.org/10.1080/00958964.1990.9943043

Nunnally, J. C., \& Bernstein, I. (1994). The assessment of reliability. Psychometric Theory, 3(1), 248-292.

Osbaldiston, R., \& Schott, J. P. (2012). Environmental sustainability and behavioral science: Meta-analysis of proenvironmental behavior experiments. Environment and Behavior, 44(2), 257-299. https://doi.org/10.1177/0013916511402673.

Otto, S., \& Kaiser, F. G. (2014). Ecological behavior across the lifespan: Why environmentalism increases as people grow older. Journal of Environmental Psychology, 40, 331-338. https://doi.org/10.1016/j.jenvp.2014.08.004

Pan, J., Chen, Y., Zhang, H., Bao, M., \& Zhang, K. (2016). Strategic Options to Address Climate Change. Climate and Environmental Change in China: 1951-2012 (pp. 129-137). Berlin: Springer. https://doi.org/10.1007/978-3-662-48482-1_7

Phipps, M., Ozanne, L. K., Luchs, M. G., Subrahmanyan, S., Kapitan, S., Catlin, J. R., ... Simpson, B. (2013). Understanding the inherent complexity of sustainable consumption: A social cognitive framework. Journal of Business Research, 66(8), 1227-1234. https://doi.org/10.1016/j.jbusres.2012.08.016

Pollock, R. M., \& Whitelaw, G. S. (2005). Community-based monitoring in support of local sustainability. Local Environment, 10(3), 211-228. https://doi.org/10.1080/13549830500075438

Robertson, J. L., \& Barling, J. (2013). Greening organizations through leaders' influence on employees' pro-environmental behaviors. Journal of Organizational Behavior, 34(2), 176-194. https://doi.org/10.1002/job.1820

Schwartz, S. H. (2012). An overview of the Schwartz theory of basic values. Online Readings in Psychology and Culture, 2(1), 11. https://doi.org/10.9707/2307-0919.1116

Soyez, K., Smirnova, M. M., \& Francis, J. N. (2015). What Triggers Pro-Environmental Behavior Cross-Culturally? An Empirical Investigation in Five Nations. The Sustainable Global Marketplace (pp. 343-343). Berlin: Springer. https://doi.org/10.1007/978-3-319-10873-5_199

Steg, L., Bolderdijk, J. W., Keizer, K., \& Perlaviciute, G. (2014). An integrated framework for encouraging pro-environmental behaviour: The role of values, situational factors and goals. Journal of Environmental Psychology, 38, 104-115. https://doi.org/10.1016/j.jenvp.2014.01.002

Stern, P. (2000). Toward a coherent theory of environmentally significant behavior. Journal of Social Issues, 
56(3), 407-424. https://doi.org/10.1111/0022-4537.00175

Tongco, M. D. C. (2007). Purposive sampling as a tool for informant selection. Ethnobotany Research and Applications, 5, 147-158. https://doi.org/10.17348/era.5.0.147-158

Turaga, R. M. R., Howarth, R. B., \& Borsuk, M. E. (2010). Pro-environmental behavior. Annals of the New York Academy of Sciences, 1185(1), 211-224. https://doi.org/10.1111/j.1749-6632.2009.05163.x

Unanue, W., Vignoles, V. L., Dittmar, H., \& Vansteenkiste, M. (2016). Life goals predict environmental behavior: Cross-cultural and longitudinal evidence. Journal of Environmental Psychology, 46, 10-22. https://doi.org/10.1016/j.jenvp.2016.02.001

Verplanken, B., \& Aarts, H. (1999). Habit, attitude, and planned behaviour: is habit an empty construct or an interesting case of goal-directed automaticity? European Review of Social Psychology, 10(1), 101-134. https://doi.org/10.1080/14792779943000035

Verplanken, B., \& Orbell, S. (2003). Reflections on Past Behavior: A Self-Report Index of Habit Strength1. $\begin{array}{lllll}\text { Journal of Applied } & \text { Social } & \text { Psychology, } & 33(6), & 1313-1330 .\end{array}$ https://doi.org/10.1111/j.1559-1816.2003.tb01951.x

Vésteinsdóttir, V., Reips, U. D., Joinson, A., \& Thorsdottir, F. (2017). An item level evaluation of the Marlowe-Crowne Social Desirability Scale using item response theory on Icelandic Internet panel data and cognitive interviews. Personality and Individual Differences, 107, 164-173. https://doi.org/10.1016/j.paid.2016.11.023

Von Borgstede, C., \& Biel, A. (2002). Pro-environmental behavior: Situational barriers and concern for the good at stake.

Wood, B. E., Cornforth, S., Beals, F., Taylor, M., \& Tallon, R. (2016). Sustainability champions? Academic identities and sustainability curricula in higher education. International Journal of Sustainability in Higher Education, 17(3), 342-360. https://doi.org/10.1108/ijshe-12-2014-0171

Zhao, H. H., Gao, Q., Wu, Y. P., Wang, Y., \& Zhu, X. D. (2014). What affects green consumer behavior in China? A case study from Qingdao. Journal of Cleaner Production, 63, 143-151. https://doi.org/10.1016/j.jclepro.2013.05.021

\section{Copyrights}

Copyright for this article is retained by the author(s), with first publication rights granted to the journal.

This is an open-access article distributed under the terms and conditions of the Creative Commons Attribution license (http://creativecommons.org/licenses/by/4.0/). 